NBER WORKING PAPER SERIES

\title{
LOSS AVERSION AND SELLER BEHAVIOR: EVIDENCE FROM THE HOUSING MARKET
}

\author{
David Genesove \\ Christopher Mayer \\ Working Paper 8143 \\ http://www.nber.org/papers/w8143 \\ NATIONAL BUREAU OF ECONOMIC RESEARCH \\ 1050 Massachusetts Avenue \\ Cambridge, MA 02138 \\ March 2001
}

Genesove: Department of Economics, Hebrew University of Jerusalem, the National Bureau of Economic Research, and the Centre for Economic Policy Research. Mayer: The Wharton School, University of Pennsylvania. We are especially indebted to Debbie Taylor for providing LINK's weekly listing files and many helpful suggestions. We also wish to thank Paul Anglin, Rachel Croson, Gary Engelhardt, Ed Glaeser, Donald Haurin, Laurie Hodrick, Glenn Hubbard, Gur Huberman, Robert Shiller, Richard Thaler, and seminar participants at various institutions for many helpful and insightful comments. The excellent research assistance of Margaret Enis, Meeta Anand, Rupa Patel, Karen Therien, and Per Juvkam-Wold is also appreciated. Research funding from the Maurice C. Falk Institute for Economic Research in Israel is acknowledged. The views expressed herein are those of the authors and not necessarily those of the National Bureau of Economic Research.

(C) 2001 by David Genesove and Christopher Mayer. All rights reserved. Short sections of text, not to exceed two paragraphs, may be quoted without explicit permission provided that full credit, including $\odot$ notice, is given to the source. 
Loss Aversion and Seller Behavior: Evidence from the Housing Market

David Genesove and Christopher Mayer

NBER Working Paper No. 8143

March 2001

JEL No. L10, R21, R31

\begin{abstract}
$\underline{\text { ABSTRACT }}$
Data from downtown Boston in the 1990s show that loss aversion determines seller behavior in the housing market. Condominium owners subject to nominal losses 1) set higher asking prices of 25-35 percent of the difference between the property's expected selling price and their original purchase price; 2) attain higher selling prices of 3-18 percent of that difference; and 3) exhibit a much lower sale hazard than other sellers. The list price results are twice as large for owneroccupants as investors, but hold for both. These findings are consistent with prospect theory and help explain the positive price-volume correlation in real estate markets.
\end{abstract}

David Genesove

Department of Economics

Hebrew University of Jerusalem

Mt. Scopus

Jerusalem 91905 Israel

and NBER
Christopher Mayer

The Wharton School University of Pennsylvania 314 Lauder-Fischer Hall 256 South $37^{\text {th }}$ Street

Philadelphia, PA 19104-6330 


\section{Introduction}

Housing markets exhibit a number of puzzling features for an asset market. In a boom, houses sell quickly at prices close to, and many times above, the sellers' asking prices. In a bust, however, homes tend to sit on the market for long periods of time with asking prices well above expected selling prices, and many sellers eventually withdraw their properties without sale. Sales volume can fall 50 percent or more from peak to trough in a real estate cycle. Although the most dramatic examples along these lines are in local markets, ${ }^{1}$ a strong positive correlation between aggregate prices and trading volumes has also been documented at the national level in the US, Great Britain, and France [Ortalo-Magne and Rady, 1998 and Stein, 1995]. These observations suggest that sellers' reservation prices may be less flexible downwards than buyers' offers. This pattern is especially puzzling given that most moves are local, so that the typical seller is also a buyer in that same market.

The Boston condominium market exemplifies this strong cyclical pattern. Between 19821989 nominal prices rose about 170 percent, then fell more than 40 percent in the next four years, stabilized over the next two, then rose again, eclipsing their previous peak by the beginning of 1998 (Figure 1). These swings in prices were accompanied by significant movement in the sales and listing behavior of sellers. At the market trough in 1992, the average asking price for new listings exceeded the expected selling price by about 35 percent, while fewer than 30 percent of listed units sold within 180 days on the market. Despite inventory levels of around 1,500 available condominiums, fewer than 750 sales took place in that year. As the housing market

${ }^{1}$ In the city of Cleveland, total single-family home sales fell from 5,289 in 1978 to 2,074 in the recession of 1982, and then increased to 4,099 by 1994 when the housing market improved. The Denver Board of Realtors reports that housing sales went from 25,212, to 14,248 to 29,710 over the same years. Data from multiple listings services in the Dallas, Houston, Minneapolis, and Phoenix housing markets exhibit a similar pattern over this time period as well. 
recovered, this pattern reversed itself. In 1997, new properties for sale had listing prices that were only 12 percent above their expected selling prices and more than 60 percent of these new listings sold within 180 days. Inventory levels varied between 500 to 850 properties and 1500 properties were sold. ${ }^{2}$

The persistence of a large inventory of units for sale and the extent of overpricing of new listings in a bust suggests that sellers may be unable or unwilling to accept market prices for property in the down part of the cycle. To motivate such behavior, we turn to loss aversion and prospect theory [Kahneman and Tversky 1979, Tversky and Kahneman, 1992]. Prospect theory argues, in part, that individuals make financial decisions relative to some reference point, suggesting that otherwise identical persons might act differently based on the price they paid for an asset. To explain loss aversion, also known as the disposition effect, prospect theory suggests that an individual's value function is concave in gains but convex in losses, and much more sensitive to losses than to equivalent-sized gains (Figure 2).

This paper shows that loss aversion helps explain seller behavior in the residential real estate market. When house prices fall after a boom, as in Boston, many units have a market value below what the current owner paid for them. Owners who are averse to losses will have an incentive to attenuate that loss by deciding upon a reservation price that exceeds the level they would set in the absence of a loss, and so set a higher asking price, spend a longer time on the market and receive a higher transaction price upon a sale.

We focus on the previous nominal purchase price as the reference point because existing

${ }^{2}$ Miller and Sklarz (1986) document the same cyclical pattern of prices, sales volume, probability of sale, inventory, and time on the market in Hawaii and Salt Lake City during the 1970s and early 1980s. In the Phoenix area, local Multiple Listing Service data shows that in the late 1980s, as home prices fell, the number of new listings remained high and overall sales volume was relatively low. When the market recovered in the mid 1990s, sales volume increased by nearly 75 percent despite a decline in the number of new listings. 
research suggests that people often focus on nominal levels in making financial decisions. ${ }^{3}$ In addition, previous analysis shows individual stock market investors are more likely to sell nominal winners than losers [Odean 1998]. ${ }^{4}$

The support for nominal loss aversion in the Boston condominium market is quite striking. Sellers whose expected selling price falls below their original purchase price set an asking price that exceeds the asking price of other sellers by between 25 and 35 percent of the percentage difference between the two. The bounds are developed from an empirical model that allows for a correlation between a unit's unobserved quality and the measure of prospective loss. In addition, we find that sellers facing a smaller loss have a much higher marginal mark-up of list price over expected selling price than sellers facing a larger loss. We also reject the hypothesis that losses are calculated in real terms. Finally, we show that both investors and owneroccupants behave in a loss averse fashion, although investors exhibit about one-half of the degree of loss aversion as owner-occupants.

The evidence on loss aversion is not confined to asking prices and is not driven solely by unsuccessful sellers. While the sensitivity of asking price to nominal loss among successful sellers is about half that of owners that eventually withdraw from the market, the coefficient

${ }^{3}$ For example, households exhibit a strong preference for nominal wages that increase over time, rather than a flat or declining earnings pattern [Lowenstein and Sicherman 1991]. Shafir, Diamond, and Tversky [1997] argue that money illusion ("a deviation from 'real' decision making") is common in a wide variety of contexts and does not go away with learning. They find that a majority of survey respondents focus on nominal instead of real gains in assessing hypothetical gains/losses in selling a house.

${ }^{4}$ The fact that stock market investors are reluctant to sell losers relative to winners is especially surprising given the capital gains tax cost associated with realizing gains and the tax benefit associated with realizing losses. Odean rejects other explanations for this behavior, including portfolio re-balancing or lower trading costs associated with low-priced stocks. Grinblatt and Keloharju [1999] and Shapira and Venezia [2001] obtain similar results for Finnish and Israeli investors, respectively. 
remains large and statistically significant. This finding also shows that loss aversion has the additional effect of driving those most sensitive to losses out of the market. Second, transaction prices are also higher. Non-linear sales price regressions indicate that the coefficients on nominal loss are also positive, although only the upper bound is large and significant. Since the cost of demanding a higher price is a longer expected time to sale, an immediate corollary to these results is that those at risk of a nominal loss should also face a longer time on the market. Indeed, we find that a 10 percent difference between the previous selling price and the current market value for sellers facing a loss results in a 3 to 6 percent decrease in the weekly hazard rate of sale. Thus the high asking prices set by those with a potential loss are not simply brief and irrational 'wish' statements that the market quickly corrects.

An alternative, and often suggested, explanation for the positive price-volume correlation is down payment requirements in the mortgage market. ${ }^{5}$ Our previous paper [Genesove and Mayer 1997] documented that liquidity constraints help determine list prices, selling prices, and time on the market for potential sellers in this market. However, in our regressions below, liquidity constraints, though still significant, appear less important than loss aversion in explaining these outcome variables.

The paper proceeds as follows. A more detailed discussion of the previous literature follows in the next section. The data is described in the third section. Section 4 develops the econometric framework. The next section presents the empirical results from list prices, followed by a section that explores the impact of loss aversion on selling prices and time on the

${ }^{5}$ In Stein [1995], down payment requirements add a self-reinforcing mechanism to demand shocks to generate a positive price-volume correlation at the aggregate level. Owners with limited home equity choose not to sell because they would have little money left for a down payment on a new property and would thus be forced to trade down if they moved. OrtaloMagné and Rady [1998] generate the same correlation using a life-cycle model with down payment constraints, in which shocks to credit availability and current income affect the timing of young households' moves up the property ladder. 
market. The paper concludes with a discussion of both the empirical findings and a future research agenda.

\section{Prospect Theory and an Empirical Model of Prices and Loss Aversion}

Previous evidence on loss aversion has relied on the effect of a prospective nominal loss on the propensity to sell an asset. Housing is transacted in a search environment, where the asset holder decision is not simply to sell or not at a given market price, but what offers to accept. A seller facing a prospective loss can attenuate it by accepting only relatively high offers - i.e., by setting a high reservation price - at the cost of a longer time on the market. We do not observe the reservation price itself, but we can infer changes in it by looking at the list price at the date of entry, the transaction price, should there be a sale, and time on the market. Genesove and Mayer, 1997, followed a similar strategy. We start by looking at the determinants of the original asking price for a property that first enters the market, for ease of presentation of our bounds model.

Below we lay out our ideal econometric formulation for the relationship between list price and potential loss. Unfortunately, estimation of this 'true' relationship is not feasible, since for any given unit we can not separately identify its unobserved quality from the extent to which the owner over- or underpaid relative to the market value at the time of purchase. We show, however, that regressing the list price on observed loss, while controlling for the previous sale price, yields a lower bound for the true coefficient on loss, while not controlling for the previous sales prices provides an upper bound for the true effect. ${ }^{6}$

${ }^{6} \mathrm{We}$ also considered a third, instrumental variables (IV) estimator analogue of the first estimator, in which a loss term based only on changes in the market index is used as an instrument in place of LOSS. This provides a biased estimate of the true effect, but an appropriate test statistic for the null of zero effect. The results of the IV estimator are consistent with the two models presented here, but noisier. See the previous working paper version for details. 
Our ideal econometric specification states that the log asking price, $L$, is a linear function of the expected log selling price in the quarter of listing, $\mu$, and an indicator of potential loss, LOSS :

$$
L_{i s t}=\alpha_{0}+\alpha_{1} \mu_{i t}+m \operatorname{LOSS}_{i s t}^{*}+\epsilon_{i t}
$$

Here, $i$ indicates the unit, $s$ the quarter of the previous sale, and $t$ the quarter of original listing. In turn, we assume that the expected log selling price is a linear function of observable attributes, the quarter of listing (entry on the market), and an unobservable component:

$$
\mu_{i t}=X_{i} \beta+\delta_{t}+v_{i}
$$

where $X_{i}$ is a vector of observable attributes, $\delta_{t}$ is a time-effect that shifts expected price proportionally, and $v_{i}$ is unobservable quality.

$L O S S^{*}$ is simply the difference between the previous log selling price, $P^{0}$, and the expected log selling price, truncated from below at zero. Thus $\operatorname{LOSS^{*}}{ }_{i s t}=\left(P_{i s}^{0}-\mu_{i t}\right)^{+}$, where $x^{+}$ $\equiv \max (0, x)$. Note that this is not a measure of loss actually incurred, but the percentage loss the potential seller would incur, were he to sell at the current average price in the market.

Assuming that equation (2) holds in all periods, we can write the previous selling price as

$$
P_{i s}^{0}=\mu_{i s}+w_{i s}=X_{i} \beta+\delta_{s}+v_{i}+w_{i s},
$$

where $w_{i s}$ is the difference between the previous selling price and its expected value, conditional on quality attributes. Thus the true loss term is $\operatorname{LOSS}_{i s t}^{*}=\left(\mu_{i s}+w_{i s}-\mu_{i t}\right)^{+}=\left(\left(\delta_{s}-\delta_{t}\right)+w_{i s}\right)^{+}$. Notice that $\operatorname{LOSS}^{*}$ is composed of two terms. The first, $\left(\delta_{s}-\delta_{t}\right)$, the change in the market price 
index between the quarter of original purchase and the quarter of listing. The second term, $w_{i s}$, is the over or underpayment by the current owner when he originally bought the house and thus is idiosyncratic to the particular transaction.

Combining the above yields

$$
L_{i s t}=\alpha_{0}+\alpha_{1} X_{i} \beta+\alpha_{1} \delta_{t}+m\left(\delta_{s}-\delta_{t}+w_{i s}\right)^{+}+\alpha_{1} v_{i}+\epsilon_{i t .} .
$$

This equation can not be estimated because $v$ and $w$, and so $L O S S^{*}$, are not observed. Thus we are led to consider alternative, feasible models.

Our first feasible model (Model I) substitutes a noisy measure of loss for true loss:

$$
L_{i s t}=\alpha_{0}+\alpha_{1}\left(X_{i} \beta+\delta_{t}\right)+m \operatorname{LOSS}_{i s t}^{I}+\eta_{i t}
$$

$$
\operatorname{LOSS}_{i s t}=\left(P_{i s}^{0}-X_{i} \beta-\delta_{t}\right)^{+}=\left(\delta_{s}-\delta_{t}+v_{i}+w_{i s}\right)^{+} .
$$

LOSS is estimated as the truncated difference between the purchase price and the predicted price from a hedonic equation. Substituting (6) into (5), we see that the error, $\eta_{i}$, contains two terms in addition to $\epsilon_{i t}$ :

$$
\eta_{i t}=\alpha_{1} v_{i}+m\left(\left(\delta_{s}-\delta_{t}+w_{i s}\right)^{+}-\left(\delta_{s}-\delta_{t}+v_{i}+w_{i s}\right)^{+}\right)+\epsilon_{i t}
$$

These additional terms lead to two biases in this model. The first arises from the simultaneous occurrence of $v_{i}$, in both the error term and observed loss term. This leads $\eta$ to be positively correlated with LOSS and so will tend to bias upwards the estimate of $m$, the coefficient on LOSS. Intuitively, a large positive discrepancy between the previous sale price and 
the unit's expected selling price may either indicate that the unit is more valuable than its measured attributes would indicate or, alternatively, that the current seller "overpaid" for the unit. The second bias is the usual errors in variable (EIV) bias, albeit in nonlinear form. The well know attenuation result for the linear EIV problem leads one to expect EIV to bias downwards the absolute value of the OLS estimate of $m$. However, the general case for attenuation can not be made, both because of the presence of other variables, and because of the non-linearity; indeed, one can construct cases of upward bias in a bivariate regression, although the inflation is quite small. Yet, given the empirical distribution of $\delta_{s}-\delta_{t}$, and assuming normality of $w$ and $v$, the simulations discussed in Appendix 2 show that EIV always leads to attenuation. Those same simulations show the first bias always dominates the second, so that the estimate is biased upwards. Also, note that under the null of no loss effect, the EIV bias does not exist.

We follow a two stage estimation procedure. We first obtain consistent estimates of $\beta$ and $\delta$ by regressing selling price on attributes and the quarter of entry dummies, corresponding to equation (2), and then substituting these estimates into equation (7) to obtain estimates of $m$, and the other coefficients. Standard errors are corrected by the method described in Newey and McFaddden [1994, p. 2183]. We do not restrict the coefficients on the predicted baseline price and the market index to be equal.

Our second feasible model (Model II) adds the residual of the previous selling price from the price regression, $v+w$, as a noisy proxy for unobserved quality, $v$ :

$$
\begin{aligned}
L_{i s t} & =\alpha_{0}+\alpha_{1}\left(X_{i} \beta+\delta_{t}\right)+\alpha_{1}\left(P_{i s}^{0}-X_{i} \beta-\delta_{s}\right)+m \operatorname{LOSS}_{i s t}+u_{i t} \\
& =\alpha_{0}+\alpha_{1} X_{i} \beta+\alpha_{1} \delta_{t}+\alpha_{1}\left(v_{i}+w_{i s}\right)+m \operatorname{LOSS}_{i s t}+u_{i t}
\end{aligned}
$$

Unfortunately, we now face the opposite problem to that in Model I. Again, the residual, $\mathrm{u}_{\mathrm{it}}$, contains two additional terms: 


$$
u_{i t}=-\alpha_{1} w_{i s}+m\left(\left(\delta_{s}-\delta_{t}+w_{i s}\right)^{+}-\left(\delta_{s}-\delta_{t}+v_{i}+w_{i s}\right)^{+}\right)+\epsilon_{i t}
$$

There are again two separate biases. As in the previous model there is measurement error, which disappears under the null, and tends to bias the OLS estimate downwards in absolute value in our simulations. The bias from unobserved quality, $v$, is gone, and in its place $-\alpha_{1} w_{i s}$ appears; as this is negatively correlated with LOSS, it will tend to bias its coefficient downwards. The argument is a little tricky, because $-\alpha_{1} w_{i s}$ is also correlated with the noisy proxy $\left(v_{i}+w_{i s}\right)$, and in principle this can offset the negative bias on $m$ that one would expect from the correlation with LOSS. However, our simulations show that this is not a serious concern.

Prospect theory implies a sensitivity to the reference point, that is, the previous price, among gainers as well as losers. Nonetheless, we have modelled the list price as a function of loss, but not gain. Model II should make clear why we do so. Our noisy proxy for unobserved quality, $P^{0}{ }_{i s}-X_{i} \beta-\delta_{s}$, is the sum of the gain and loss, and so we can not include all three among our regressors. Thus one is free to interpret the coefficient on LOSS as the differential effect of a loss relative to a gain, and the coefficient on the noisy quality proxy in Model II as the sum of the effects of a gain and unobserved quality. We have, nonetheless, chosen to speak only of losses and unobserved quality because prospect theory claims a much greater sensitivity to the reference point for losses than for gains, and because the first order in establishing the relevance of prospect theory here lies in assuring that our estimates are not driven merely by unobserved quality.

\section{Data: Sources and Summary}

Our data track individual property listings in the Boston Condominium market at weekly intervals between 1990 and 1997. LINK, a privately owned listing service which claims to have had a 90 to 95 percent market share in a well-defined and geographically segmented market area 
in downtown Boston, provides the date of entry and exit, the listing price on the day of entry, the type of exit, and the sale price, if any, for each property. The type of exit is deemed a "sale" if a sale record was found in LINK, and "withdrawal" otherwise. We supplement LINK data with information on property characteristics and assessed tax valuations obtained from the City of Boston Assessor's Office. The Assessor's data also indicate whether the owner applied for a residential tax exemption in 1992. Banker and Tradesman, another proprietary data set, provides information on all sales and refinancings since 1982, including the sales price, sales date, and mortgage amount. These data allow us to recover the previous sales prices, and to construct the outstanding mortgage. Appendix 1 describes the regression of transaction prices on attributes and quarter of sale dummies, by which we compute the expected selling price in the quarter of entry, which we need to form the LOSS and loan to value (LTV) measures.

Table I summarizes the data. Clearly this is not a cross-section of typical properties in the U.S. The average property has an assessed value on January 1, 1990 of \$212,833, despite having only 936 square feet, and well above the average value of about $\$ 180,000$ for Boston area singlefamily homes. Owners also have high incomes, and presumably high levels of non-housing wealth, and thus should be relatively sophisticated compared to most US home owners. Fiftyfive percent of listed properties had a current expected selling price in the quarter of listing that was lower than the previous purchase price, thus subjecting their owners to a potential loss. The typical owner has a mortgage whose balance at the time of listing is 63 percent of the estimated value of the property at that date, well above the US average of about one-third. The LTV ratio is high in this market for three reasons: market prices fell over $40 \%$ during the sample period, high prices lead buyers to take on more debt when initially purchasing a home [see Engelhardt, 1998], and many households in the area are young with steep age-earnings profiles (i.e., yuppies).

\section{Estimates From List Price and Selling Price Regressions}


Table II presents our basic results on the relationship between list price and prospective losses. As noted above, the standard errors correct for the estimation of the 1990 baseline value and the market index (although this correction makes little quantitative difference), as well as for correlation among properties listed more than once, and are robust to heteroskedacticity. Column (1) reports the regression of list price on LOSS, the excess of LTV (the loan-to-value ratio) over 0.8 , the market index in the quarter of listing $\left(\delta_{t}\right)$, and the 1990 baseline value of the home $\left(X_{i} \beta\right){ }^{7}$ All price variables are measured in logs. The estimated coefficient of 0.35 on LOSS has the interpretation that a ten percent increase in a prospective positive loss, leads a seller to set a list price 3.5 percent higher. As argued in the previous section, this estimate should be viewed as an upper bound to the true effect of loss aversion on list prices.

Column (2) adds the difference between the previous sale price and its predicted value in its quarter of previous sale. As noted earlier, this is a noisy proxy for unobserved quality. Since the added noise is itself a component of the expected loss, the estimated coefficient on LOSS of 0.25 should provide a lower bound for the true effect. Taking the two columns together, then, we conclude that the true effect is greater than 0.25 , but less than 0.35 , a result confirmed by the simulations reported by Appendix 2.

Columns (3) and (4) add a quadratic loss term. Whether we include the previous selling price residual as in (4), or not, as in (3), we find that both the quadratic and the linear terms are separately and jointly significant, and that the estimates imply a positive, but falling, marginal response to the prospective loss for most of the range of the data. ${ }^{8}$ Obviously, sellers can not

${ }^{7}$ Genesove and Mayer [1997] justifies truncating LTV at 0.8. Similar results obtain when using the index of the quarter prior to entry instead.

${ }^{8}$ In separate regressions not reported here, we included a quadratic gain term in addition to the quadratic loss. (Section II explained why we can not include a linear gain term.) The coefficient on the quadratic gain was positive and highly significant, suggesting that the marginal effect of gain, which we would expect to be negative, diminishes in absolute value as the gain 
raise the list price indefinitely without pricing themselves out of the market.

We also find a positive response to LTV. We expected to find this from previous work [Genesove and Mayer 1997]. However, at 0.06, the effect is less than half what we previously found. The higher estimate in the earlier work derives in part from the absence of LOSS in those regressions, where LTV was obviously picking up some of the loss aversion effect. However, the two estimates are not directly comparable, because of the different time periods, the inclusion of all, not only sold, properties here, and the need to define market value somewhat differently here. Inclusion of the quadratic term cuts the LTV coefficient in half, while maintaining its statistical significance.

The coefficient on the Estimated Value in 1990 is 1.09, significantly greater than one, across all the columns. This result is consistent with simple bargaining theory, given that the distribution of the regressor is right skewed. With higher quality units selling in a thinner market, list prices are set more than proportionately higher to allow greater room for bargaining.

Interestingly, the coefficient on the market index is significantly less than one. This suggests that list prices do not immediately adjust to changes in market prices. ${ }^{9}$ Columns (5) and (6) substitute quarterly dummies of entry for the quarterly market index. This is a more general specification that nests the linear market index derived from the price regression. Use of the quarterly dummies has no effect on the upper or lower bound estimates.

Table III considers three alternative robustness checks on our estimates. To test our maintained hypothesis that sellers calculate losses in nominal, rather than real, terms, columns (1) and (2) add REAL LOSS $S_{i s t}=\left(P_{i s}^{0}-X_{i} \beta-\delta_{t}-\pi_{s t}\right)^{+}$to our basic specifications. Here, $\pi_{s t}$ is

increases. Its inclusion had no substantive effect on the other coefficients in the regression.

${ }^{9}$ Further investigation shows that list prices require several quarters to fully adjust to changes in market conditions. We are examining the adjustment rate in current work. 
the change in the $(\log )$ consumer price index between period $s$, the date of original purchase, and period $t$, the date the property enters the market. Nearly 20 percent of the sample suffered a real, but not nominal, loss.

The coefficients on REAL LOSS are much smaller than those on LOSS. The t-statistic on the REAL LOSS coefficient can be interpreted as the non-nested test for the null hypothesis that only the nominal loss matters against the alternative hypothesis that only the real loss matters (Davidson and MacKinnon [1993, p. 387], Greene [1997, p. 365]) . It is insignificant in both columns. In contrast, the significant coefficients on the nominal loss term show that the "only real" hypothesis would be rejected in the direction of the "only nominal" hypothesis. An alternative, model selection approach would also chose the "only nominal" specification over the "only real" specification, since the R-squared statistics from the regressions with only LOSS (the first two columns of Table II) exceed those with REAL LOSS in place of LOSS (not shown) (Amemiya [1980]). Given these results, we concentrate on nominal losses elsewhere in the paper.

Columns (3) and (4) add the price index of the date of the previous sale. Recall that this term, $\delta_{\mathrm{s}}$ in the model, enters positively (and nonlinearly) into the calculation of the prospective loss. Including it separately in the regression addresses any concern that the coefficient on the prospective loss might somehow be capturing the effect of $\delta_{\mathrm{s}}$, which might in turn be proxying for some unknown selection effect. Its inclusion, in fact, pushes the upper and lower bound estimates up slightly.

Finally, we restrict the sample to properties with a loan to value ratio of less than half in columns (5) and (6). We do so to answer two possible criticisms. First, LOSS and LTV might interact in highly non-linear ways, making identification of the separate effects difficult in the full sample. Second, as we measure loan balance with error (since we do not have the exact interest rate on each mortgage), the coefficient on LOSS may really be picking up declines in the 
market that raise LTV. The estimates in the last two columns show that loss aversion is unrelated to overall wealth or credit constraints, however. The average owner in this sub-sample has at least $\$ 110,000$ in housing wealth. Yet, the coefficients on LOSS are not effected much.

\section{A. An Aside on Owner-Occupants and Investors}

Approximately 40 percent of the units in our sample are owned by investors; the rest are owned by their occupants. We might suspect the two groups to behave differently. Perhaps the psychological pain of selling one's home exceeds that of selling a mere investment. Or large investors might calculate the loss on their entire portfolio of houses, or even their entire portfolio of investment assets, although the vast majority of investors in this market are small ones. Bernartzi and Thaler [1995] argue that prospect theory should apply to professional investment managers whose performance is judged by individuals who apply the same behavioral principles when assessing their managed investments as elsewhere. ${ }^{10}$

We classify a unit as owner-occupied if the Assessor's Office's record of 1/1/92 notes that the property owner obtained a property tax exemption, which the City of Boston grants to owner-occupants. This definition leads to two additional conditions for inclusion in the sub-sample used in the next set of regressions: 1) the listing date on the property must be after $1 / 1 / 92$ and 2) there must be no sale between 1/1/92 and the listing date. We assume that there is no change in status without a sale, an event that Assessor's Office employees assure us is rare. Of course, mis-classifications will bias against finding differences between the two owner types.

Table IV compares owner-occupants to investors and strongly rejects the null that the two groups behave the same (p-value of .04). For example, in column (1) the coefficient on loss for owner-occupants is 0.50 , about twice as large as the coefficient on investors. Nonetheless, the

${ }^{10}$ The sole evidence on the effect of ownership status on loss aversion is provided by Shapira and Venezia [2001] who show that the disposition effect among professionally managed brokerage accounts, although it exists, is less than that of self-managed brokerage accounts. 
loss coefficient for investors of 0.24 is statistically significant and indicates that investors still raise their asking prices by about one-quarter of their prospective loss. Low equity appears to have a larger impact on the asking price of investors than owner-occupants, although the difference is not statistically significant. Among those who are neither equity constrained nor face a potential loss, investors also set slightly lower asking prices than owner-occupants. This is surprising given that owner-occupants face higher direct costs of listing a property over time--and higher asking prices should lead to a longer expected time to sale--because potential buyers traipse through their house, interrupting meals and requiring a constantly clean home. Perhaps owner-occupants are overly optimistic in their listing behavior.

Correcting for possible unobserved quality in column (2) reduces the coefficients on prospective loss somewhat. The owner-occupant LOSS coefficient remains large and highly significant, while the investor LOSS coefficient, while remaining economically large, becomes statistically insignificant. Columns (3) and (4) add quadratic terms for the expected loss, with and without controls for unobserved quality. We find that the joint test on the linear and quadratic loss terms is statistically significant not only for owner-occupants but also for investors, with a p-value of .001 for each test. Strikingly, the major difference between the two groups is in the quadratic terms, indicating that differential behavior arises only for large losses, for which investors mitigate their marginal response much more than owner-occupants do.

\section{B. Evidence From Sold Properties}

Skeptics might question the economic importance of asking prices, since these are not transaction prices. One might imagine that loss averse sellers set an asking price near their old purchase price, but have their thinking quickly corrected by the market, and so quickly cut their asking price. In this scenario, neither prices nor time on the market would show the influence of loss aversion.

The data indicate otherwise. Some degree of correction does occur, but it is only partial. 
The estimated coefficients on the final transaction prices are not as large as those earlier estimated for the asking price, but they are positive, although significant only for the upper bound. Part of the difference between the two sets of coefficients is explained by a lesser sensitivity to LOSS in asking price among those who eventually sell their property, rather than withdraw it from the market, and the other part reflects a reduction in the LOSS effect from list price to sale price among realized sellers. There are time on the market effects as well, with properties facing a prospective loss exhibiting a lower hazard rate of sale.

As a first test of the hypothesis that realized sellers exhibit less loss aversion than those who withdrawn their property from the market (withdrawers), Table V reports the results of rerunning the earlier list price regressions, conditioning on whether or not the property eventually sells. ${ }^{11}$ Recall that we use the list price on the day a property was first listed. Thus the list price reflects the seller's perceptions upon entering the market, when he does not yet know how the market will react to the property. Columns (1) and (2) show that realized sellers exhibit a lower degree of loss aversion than withdrawers. An F-test rejects that the coefficients on LOSS are the same for the two groups at the 10 percent level. As in the earlier regressions, the coefficients in column (2) provide a lower bound for the coefficient on LOSS. Note also the coefficient on the dummy for a sold property, which indicates that among units not subject to a loss or equity constraints, properties that eventually sell had been listed at a 3 to 4 percent lower list price.

Columns (3) and (4) include a quadratic term for LOSS, which is highly significant. As with investors and owner-occupants, most of the difference in loss aversion for these two groups stems from the quadratic term. In both columns, the marginal effect of loss aversion diminishes much more quickly with the size of the loss for realized sellers than for withdrawers.

In considering the effect of loss aversion on transaction prices, we need to simultaneously

\footnotetext{
${ }^{11} \mathrm{~A}$ small fraction of properties not observed to sell are actually right censored, rather than withdrawn from the market. Their inclusion does not affect our results.
} 
estimate the market value, $\mu_{\mathrm{it}}$, and the loss. Thus we are unable to estimate the relationship using an auxiliary regression, as for the asking price, and must estimate the model in a single stage.

We use nonlinear least squares to estimate ${ }^{12}$

$$
\begin{aligned}
P_{i s t} & =\alpha_{0}+\alpha_{1}\left(X_{i} \beta+\delta_{t}\right)+m \operatorname{LOSS}_{i s t}+u_{i t} \\
& =\alpha_{0}+\alpha_{1} X_{i} \beta+\alpha_{1} \delta_{t}+m\left(P_{i s}^{0}-X_{i} \beta-\delta_{t}\right)^{+}+u_{i t}
\end{aligned}
$$

and

$$
\begin{aligned}
P_{i s t} & =\alpha_{0}+\alpha_{1} X_{i} \beta+\alpha_{1} \delta_{t}+m\left(P_{i s}^{0}-X_{i} \beta-\delta_{t}\right)^{+}+\alpha_{1}\left(v_{i}+w_{i s}\right)+u_{i t} \\
& =\alpha_{0}+\alpha_{1} X_{i} \beta+\alpha_{1} \delta_{t}+m\left(P_{i s}^{0}-X_{i} \beta-\delta_{t}\right)^{+}+\alpha_{1}\left(P_{i s}^{0}-X_{i} \beta-\delta_{s}\right)+u_{i t}
\end{aligned}
$$

These regressions yield upper and lower bounds, respectively, of the true LOSS coefficient, $m$. Table VI shows our results. Column (1) shows our estimate of the upper bound on the coefficient on prospective loss to be 0.18 , with a standard error of 0.02 . This effect is about half of what we found in asking prices for the whole sample of owners. Two factors account for the difference. First, as the previous table showed, owners who withdraw from the market are more sensitive to loss than those who eventually sell. Second, although, as that table showed, the asking prices of eventual sellers also reflect loss aversion, with an upper bound coefficient of 0.27 , that phenomenon is partially "corrected" by the market. Nonetheless, at least in the upper bound, loss aversion is still present, and noticeably so, in the transaction prices.

Column (2) shows the results from estimating equation (11). The coefficient on LOSS,

${ }^{12} \mathrm{We}$ write equation (11) in two ways to indicate that, in estimating it, we treat observations with a previous sale prior to 1990 (the start of our sample period) differently than those with a prior sale after that date. For the first group, we use the residual from a price regression on the pre-1990 observations from Banker and Tradesman as our quality proxy, labeled in Table VI. For the second group, we use the term $P^{0}{ }_{i s}-X_{i} \beta-\delta_{s}$. We adopt this approach to avoid estimating pre-1990 quarter effects on the basis of post-1990 prices. 
.03 , is an estimate of the lower bound on the true effect. It is small and insignificant.

Finally, the coefficient on LTV in these equation is $0.06-0.07$, and highly significant. It is interesting to note that, unlike the effects of LOSS, the impact that LTV has on selling price is similar to its effect on listing price. There is a likely explanation. As LTV represents an institutional constraint on sellers' behavior, rather than a psychological reluctance to sell, its effect does not diminish with learning or exposure to market conditions.

\section{Time on the Market}

From the perspective of search theory, we would expect that if sellers facing a potential loss have higher reservation prices, as suggested above, then they must also face a longer time on the market, or equivalently, a lower hazard rate of sale. In fact, it would be quite puzzling if we did not find that sellers who obtained higher prices also had a longer time to sale.

This section estimates the contribution of loss aversion to the hazard rate of sale--the probability that a property sells in any given week given that an owner has listed the property for sale and that it has not yet sold. We specify the hazard rate as $h(t)=h_{0}(t) \exp (\theta \mathrm{Z})$, where $\mathrm{Z}$ is a vector of attributes of the property and owner, and $\theta$ is a conformable vector of parameters. We also include other property attributes in this estimating equation to allow for the possibility that the offer arrival rate varies according to quality or other unit characteristics.

We estimate the parameters by Cox's partial likelihood method [Cox and Oakes, 1984]. Units that remain listed but unsold at the end of our sample period, December 1997, are treated as right censored. Units that are de-listed without sale ("withdrawn") are considered to be censored at exit. Although some properties are withdrawn because of exogenous changes in the conditions of the household, others exit when the owners become discouraged. Under the null hypothesis of no loss aversion effect on selling, the treatment of withdrawn properties should have no effect on the estimate coefficients. Under the alternative that loss aversion does matter, 
the likely bias is positive if, precisely because they are less likely to sell, high loss properties are more likely to be withdrawn. This bias will make loss aversion more difficult to establish.

As expected, the coefficients on the prospective loss terms in Table VII are negative and highly statistically significant. To understand the difference in the estimates of Columns (1) and (2) first note the positive and significant coefficient on the Estimated Value in 1990, which indicates that high-quality properties have a higher hazard rate of sale. Thus the positive correlation between unobserved quality in the error term and in the LOSS term leads to a positive bias on LOSS in column (1). Following this line of reasoning, including our noisy proxy for quality in Column (2) would lead to a negative bias on LOSS. The results in the first two columns are consistent with that reasoning, and with our earlier findings on the bounds on the true coefficient estimates in the previous sections. The coefficients suggest that an owner facing a 10 percent prospective loss on a property will have between a $3\left(1-\mathrm{e}^{-.033}\right)$ and $6\left(1-\mathrm{e}^{-.063}\right)$ percent reduction in the weekly sale hazard, or an equivalent increase in the expected time to sale.

We add quadratic terms for LOSS in the columns (3) and (4), and once again estimate coefficients that are consistent with our previous results. Larger losses have a positive, but diminishing effect on the hazard rate of sale. This is as to be expected, given that sellers' marginal increase in their list price falls with the size of the prospective loss.

\section{Concluding Remarks}

This paper has shown that loss aversion affects seller behavior in the residential real estate market. Data from a boom-bust cycle in downtown Boston from 1990-1997 shows that sellers subject to losses: 1) set higher asking prices of 25-35 percent of the difference between the expected selling price of a property and their original purchase price; 2) attain higher selling prices of 3-18 percent of that difference, and 3) have a lower hazard rate of sale. The list price results are roughly twice as large for owner-occupants as investors, although they hold for both 
groups. For a given loss, the list price markup of realized sellers lies between the markup of withdrawers and the markup the sellers receive in the transaction price. That sellers of such an important asset to consumers exhibit loss aversion gives added credence to the documentation of such behavior in experimental settings.

The paper's results also have broader implications for our understanding of real estate markets, and why they differ from perfect asset markets. First, the mere fact that transaction prices are determined by seller characteristics in addition to unit attributes, whether that be through loss aversion or equity constraints, indicates that the market is far from being a perfect asset market. Second, a major finding of previous research is that volume falls when prices decline. This phenomenon cannot be explained by perfect asset models. Loss aversion and equity constraints can explain it, and we have shown in this paper that both forces are present. But the less than unitary coefficient on the market index in the asking price regression, and the (unreported) relative magnitudes of the quarterly dummies in the asking price and transaction price regressions indicate the effect of some additional element. We suspect that sellers' lagged adjustment to new market conditions is this third mechanism, and we are exploring that hypothesis in current research. At the same time, our findings imply that the underlying fundamentals of housing market cycles are more cyclical than they seem. Since at the trough of the cycles, loss aversion and equity constraints lead many sellers to set relatively high reservation prices, buyers valuation must actually be more volatile than the observed transaction prices! 


\section{$\underline{\text { References }}$}

Amemiya, Takeshi, "Selection of Regressors”, International Economic Review, 21 (1980), 33154.

Bernartzi, Shlomo, and Richard Thaler, "Myopic Loss Aversion and the Equity Premium Puzzle," Quarterly Journal of Economics, CX (1995), 75-92.

Cox, David Roxbee and D. Oakes, Analysis of Survival Data. (New York: Chapman and Hall, 1984.)

Davidson, Russell and James MacKinnon, Estimation and Inference in Econometrics (Oxford University Press, 1993.)

Engelhardt, Gary, "Housing Leverage and Household Mobility," Dartmouth College mimeo, 1998.

Genesove, David and Christopher Mayer, "Equity and Time to Sale in the Real Estate Market," American Economic Review, June, LXXXVII no.3, (1997) 255-269.

Genesove, David and Christopher Mayer, "Loss Aversion and Seller Behavior: Evidence from the Housing Market", Wharton School, University of Pennsylvania mimeo. February 2000 .

Greene, William, Econometric Analysis (Prentice-Hall International, Inc., 1997)

Grinblatt, Mark and Matti Keloharju, "What Makes Investors Trade?" Anderson School at the University of California, Los Angeles, Mimeo, 1999.

Kahneman, Daniel and Amos Tversky, "Prospect Theory: An Analysis of Decision Under Risk." Econometrica, March, XLVII no.2, (1979) 263-291.

Lowenstein, George and Nachum Sicherman, "Do Workers Prefer Increasing Wage Profiles?" Journal of Labor Economics, IX no.1, (1991) 67-84.

Miller, Norman and Michael Sklarz. 1986. "A Note on Leading Indicators of Housing Market Price Trends." The Journal of Real Estate Research, Fall, 1(1), pp. 115-124.

Newey, Whitney K. and Daniel McFadden, "Large Sample Estimation and Hypthesis Testing," in Robert F. Engle and Daniel L. McFadden, eds., The Handbook of Econometrics, (Amsterdam: North Holland, 1994.)

Odean, Terrance, “Are Investors Reluctant to Realize Their Losses?” Journal of Finance, LIII, (1998) 1775-1798. 
Ortalo-Magné, François, and Sven Rady, "Housing Market Fluctuations in a Life-Cycle Economy," Discussion Paper No.296, Financial Markets Group, London School of Economics, 1998.

Shafir, Eldar, Peter Diamond, and Amos Tversky, "Money Illusion," Quarterly Journal of Economics, May, CXII (1997) 341-74.

Shapira and Venezia, "Patterns of Behavior of Professionally Managed and Independent Investors," Journal of Banking and Finance, (forthcoming 2001).

Stein, Jeremy C., "Prices and Trading Volume in the Housing Market: A Model with Downpayment Constraints," Quarterly Journal of Economics, May, CX, (1995) 379-406.

Tversky, Amos and Daniel Kahneman, "Advances in Prospect Theory: Cumulative Representation of Uncertainty," Journal of Risk and Uncertainty, vol. V, (1992) 297-323. 
Appendix 1: Construction of the Data Set and Variables

The listing data are obtained from proprietary records maintained by LINK. According to LINK, 13,983 condominiums were listed for sale between 1990 and 1997, out of a total stock of a little more than 30,000 units. Since brokers sometimes try to game the system by withdrawing a property and then relisting it soon after so as to designate it as a "new listing," a new spell is considered to have begun only if there was at least an eight-week window since the property last appeared in LINK. There are a number of properties with multiple spells in the data, and we adjust the standard errors for clustering within a given property. A change or addition of a broker (properties can be listed simultaneously by as many as three brokers and sellers may switch brokers while a property remains on the marke) does not constitute a new spell.

To be included in this study, a listed condominium must meet three conditions: 1) no missing information in LINK, 2) at least one previous sale in the deeds records - with the previous mortgage and sales price, and 3) match with the assessor's data - containing property attributes and property tax records. The matching process is difficult, since many brokers list the address of a condominium as visitors would find it, not necessarily its legal address. (For example, a $6^{\text {th }}$ floor condo might be listed as a penthouse unit in LINK, but as apartment \#6 in the assessor's data; or the building, may be referred to by the project name, Parkside, in LINK, but by its legal street address in official records.) Condition (2) eliminates newly constructed properties from the sample, as well as properties whose last sale occurred prior to 1982, as there are no computerized records in the deeds data before then. These restrictions yield us 5,792 listings, which constitutes the full sample for this paper.

To be sure about any data matching biases, we had research assistants match the LINK 
data with the other data sets by hand after completing a round of computer matching. This quitecostly process increased the match rate, but had no material effect on the coefficients. Our major results are also unchanged if we drop the requirement of a previous sale, instead setting all variables requiring a previous sale equal to zero and including a dummy variable for no match in the deeds records.

In order to calculate the prospective loss and loan to value ratio, we compute a price index from a hedonic regression. The data for the hedonic regression includes all property sales reported in Banker and Tradesman between 1982 and 1997 that could be matched with the assessment data to obtain property characteristics and were located in the LINK coverage area, whether or not the properties were actually listed in LINK. This totaled 21,800 sales. The hedonic equation regresses the log of a property's selling price on 63 quarterly time dummy variables and a number of property attributes, including a separate dummy variable for each neighborhood, controls for the number of bedrooms and bathrooms, first, second, third and fourth order terms for square footage, and the property's assessed value on January 1, 1990, just prior to the beginning of the LINK sample.

We investigate two possible biases in the hedonic equation. One possibility is that the city assessed value may give biased results in an equation that includes sales prior to 1990 . However, our results remain unchanged if we drop the assessed value in 1990 and instead include dummy variables for attributes in place of linear measures (dummies for studio, onebedroom, two-bedroom, etc. in place of number of bedrooms.; one bath, two-bath, etc. in place of number of baths.; and dummies for floor 1-4, floor 5-10, floor 11 and above). Without the assessed value, the hedonic equations are less accurate and generate slightly wider bounds on the 
LOSS coefficient. Also, we consider the possibility that market booms and busts might have a differential impact on the market prices of different types of condominiums, leading to a possible correlation between LOSS and the mismeasurement of the actual expected price. To address this issue, we have re-run the basic regression in Model I allowing the value of property attributes to vary every year. The coefficient on LOSS increases slightly to 0.38 from 0.35 , suggesting that our results are not being driven by such misspecification.

The current loan balance is computed by amortizing the original mortgage amount (or a refinanced amount) using average mortgage rates prevailing in the market in the month of origination.

\section{Appendix 2: Simulation of Biases}

This appendix describes our calculation of the expected biases in the coefficient on LOSS in the basic model of list price. Our primary purpose in calculating these biases is to ensure that our intuition on the sign of these biases, as described in the text, is correct. We also discuss the likely size of the biases.

In calculating the biases for each of the two models, we assume that the unobserved quality and idiosyncratic component, $v$ and $w$, are each normally distributed, with mean zero and variances $\sigma^{2}$ and $\sigma^{2}{ }_{w}$, respectively. By construction, the two are independent of each other. Although these variables are latent, we do observe their sum, so we will be interested in the conditional distribution of $v$, given $v+w$. This is a normal distribution with mean $(v+w) \sigma_{v}^{2} /\left(\sigma_{v}^{2}+\sigma^{2}{ }_{w}\right)$ and variance $\sigma^{2}{ }_{w} \sigma^{2} /\left(\sigma_{v}^{2}+\sigma^{2}{ }_{w}\right)$.

Thus, e.g., when the distribution of $w$ is degenerate, knowing $v+w$ is equivalent to 
knowing $v$ : the conditional mean of $v$ is $v+w$ and its variance is zero; in contrast, when the variance of $v$ is small compared to the variance of $w$, the conditional distribution is close to the unconditional distribution. As our estimate of the variance of $v+w, \sigma^{2}{ }_{v}+\sigma^{2}{ }_{w}$, we take the mean squared residual from the first stage price regression described in Section 4, which is equal to $.35^{2}$.

We calculate the biases on a grid of $\sigma_{v}$, from zero (for which all the biases are zero) to .35. We drew 100,000 draws from the data set with repetition. With each such draw, we also drew a random draw of $v$ from the distribution described above, conditional on the observed value of $v+w$ for that observation.

Let $X$ be the $\mathrm{k}$ by 100,000 matrix of data, where $\mathrm{k}$ is the number of regressors. Let $\mathrm{m}^{\mathrm{j}}$ be the estimate of the LOSS coefficient in model $\mathrm{j}$. Thus $\mathrm{m}^{\mathrm{I}}=.35$, from Column (1) of Table II. Our estimate of the first bias term in Model $\mathrm{I}$ is $\mathrm{B}_{1}^{\mathrm{I}}=\left(X^{\prime} X\right)^{-1} X^{\prime} v$. (We are assuming that $\alpha_{1}=1$.) Define the second error component (the errors-in-variable component) $\eta_{1}=\left(\delta_{s}-\delta_{t}+w_{i s}\right)^{+}-\left(\delta_{s}\right.$ $\left.-\delta_{t}+v_{i}+w_{i s}\right)^{+}$. Our estimate of the second bias term in Model I is $\mathrm{mB}_{2}^{\mathrm{I}}=\mathrm{m}\left(X^{\prime} X\right)^{-1} X^{\prime} \eta_{l}$. Thus the overall bias for Model I is $B^{I}=m^{I}-m=B_{1}^{I}+m^{I}{ }_{2}=\left(m^{I} B_{2}^{I}+B_{1}^{I}\right) /\left(1+B_{2}^{I}\right)$ (where we have left out the plims).

Likewise, our estimate of the first bias term in Model II is $\mathrm{B}_{1}^{\mathrm{II}}=-\left(X^{\prime} X\right)^{-1} X^{\prime} \mathrm{w}$. Our estimate of the second bias term in Model II is $\mathrm{mB}_{2}^{\mathrm{II}}=\mathrm{m}\left(X^{\prime} X\right)^{-1} X^{\prime} \eta_{1}$. (Note that $\mathrm{B}_{2}^{\mathrm{I}} \neq \mathrm{B}_{2}{ }_{2}$, since the set of regressors in the two models differ.) The overall bias for Model I is $\mathrm{B}^{\mathrm{II}}=\left(\mathrm{m}^{\mathrm{II}} \mathrm{B}_{2}^{\mathrm{II}}+\mathrm{B}_{1}^{\mathrm{II}}\right) /\left(1+\mathrm{B}_{2}^{\mathrm{II}}\right)$.

We find that $\mathrm{B}^{\mathrm{I}}$ is always positive and increasing in $\sigma_{v}$, while $\mathrm{B}^{\mathrm{II}}$ is negative and decreasing in the same. This accords with the intuition given in Section 4, which is drawn from well known results on a missing regressor and errors-in-variables in a bivariate regression model. 
Thus $\mathrm{m}^{\mathrm{I}}$ is indeed an upper bound, and $\mathrm{m}^{\mathrm{II}}$ a lower bound, for a consistent estimate of the true coefficient.

If the model of Section 4 is true, $\operatorname{plim}\left(\mathrm{m}^{\mathrm{I}}-\mathrm{B}^{\mathrm{I}}\right)=\operatorname{plim}\left(\mathrm{m}^{\mathrm{II}}-\mathrm{B}^{\mathrm{II}}\right)$. This identifies a unique value of $\sigma_{v}: \mathrm{B}^{\mathrm{I}}-\mathrm{B}^{\mathrm{II}}=\mathrm{m}^{\mathrm{II}}-\mathrm{m}^{\mathrm{I}}=.1$ at $\sigma_{v}=.07$. As a check on this value, consider the coefficient on $v+w$ in Model II, which we estimate in Column (2) of Table II at .11. We calculated the bias on this coefficient in an analogous manner to the above. This bias increases from -.97 to -.08, as $\sigma_{v}$ increases from zero to .35 . At $\sigma_{v}=.07$, the calculated bias on the coefficient is -.93 , which accords well with an estimated value of .11, and a "true" value of 1 . 


\section{Table I}

Sample Means (Standard Deviations in Parentheses)

\begin{tabular}{|c|c|c|}
\hline Variable & All listings & Listings that were sold \\
\hline Number of observations & 5,785 & 3,408 \\
\hline \multirow[t]{2}{*}{1991 assessed value $^{a}$} & $\$ 212,833$ & $\$ 223,818$ \\
\hline & $(132,453)$ & $(135,553)$ \\
\hline \multirow[t]{2}{*}{ Original asking price } & $\$ 229,075$ & $\$ 242,652$ \\
\hline & $(193,631)$ & $(202,971)$ \\
\hline \multirow[t]{2}{*}{ Sales price } & N.A. & $\$ 220,475$ \\
\hline & & $(180,268)$ \\
\hline \multirow[t]{2}{*}{ Loan/value (LTV) ${ }^{\mathrm{b}}$} & 0.63 & 0.59 \\
\hline & $(0.42)$ & $(0.41)$ \\
\hline Percent with $\mathrm{LTV}^{\mathrm{b}}>80 \%$ & $38 \%$ & $32 \%$ \\
\hline Percent with LTV $^{\mathrm{b}}>100 \%$ & $19 \%$ & $15 \%$ \\
\hline Percent with last sale price $>$ & $55 \%$ & $50 \%$ \\
\hline \multicolumn{3}{|l|}{ Predicted selling price ${ }^{b}$} \\
\hline \multirow[t]{2}{*}{ Square footage } & 936 & 977 \\
\hline & $(431)$ & $(444)$ \\
\hline \multirow[t]{2}{*}{ Bedrooms } & 1.5 & 1.6 \\
\hline & $(0.7)$ & $(0.7)$ \\
\hline \multirow[t]{2}{*}{ Bathrooms } & 1.2 & 1.2 \\
\hline & $(0.4)$ & $(0.4)$ \\
\hline \multirow[t]{2}{*}{ Months since last sale } & 66 & 66 \\
\hline & $(37)$ & $(38)$ \\
\hline
\end{tabular}

a The 1991 assessed value comes from the City of Boston Assessor's Office. It is the estimated market value of the property as of $1 / 1 / 90$, the beginning of the sample period, and contains no 
information from sales after that date.

${ }^{\mathrm{b}}$ The predicted value is for the quarter that the property enters the market and comes from a hedonic regression over the sample period using all sold properties. Regression results are available from the authors. 


\section{Table II}

Loss Aversion and List Prices (Dependent Variable: Log(Original Asking Price),

OLS equations, standard errors in parentheses

\begin{tabular}{|c|c|c|c|c|c|c|}
\hline Variable & $\begin{array}{c}\text { (1) } \\
\text { All } \\
\text { listings }\end{array}$ & $\begin{array}{c}\text { (2) } \\
\text { All } \\
\text { listings }\end{array}$ & $\begin{array}{c}\text { (3) } \\
\text { All } \\
\text { listings }\end{array}$ & $\begin{array}{c}\text { (4) } \\
\text { All } \\
\text { listings }\end{array}$ & $\begin{array}{c}\text { (5) } \\
\text { All } \\
\text { listings }\end{array}$ & $\begin{array}{c}\text { (6) } \\
\text { All } \\
\text { listings }\end{array}$ \\
\hline LOSS & $\begin{array}{l}0.35 \\
(0.06)\end{array}$ & $\begin{array}{c}0.25 \\
(0.06)\end{array}$ & $\begin{array}{c}0.63 \\
(0.04)\end{array}$ & $\begin{array}{c}0.53 \\
(0.04)\end{array}$ & $\begin{array}{c}0.35 \\
(0.06)\end{array}$ & $\begin{array}{c}0.24 \\
(0.06)\end{array}$ \\
\hline LOSS-squared & & & $\begin{array}{l}-0.26 \\
(0.04)\end{array}$ & $\begin{array}{l}-0.26 \\
(0.04)\end{array}$ & & \\
\hline LTV & $\begin{array}{c}0.06 \\
(0.01)\end{array}$ & $\begin{array}{l}0.05 \\
(0.01)\end{array}$ & $\begin{array}{c}0.03 \\
(0.01)\end{array}$ & $\begin{array}{c}0.03 \\
(0.01)\end{array}$ & $\begin{array}{c}0.06 \\
(0.01)\end{array}$ & $\begin{array}{c}0.05 \\
(0.01)\end{array}$ \\
\hline $\begin{array}{l}\text { Estimated value in } \\
1990\end{array}$ & $\begin{array}{c}1.09 \\
(0.01)\end{array}$ & $\begin{array}{c}1.09 \\
(0.01)\end{array}$ & $\begin{array}{c}1.09 \\
(0.01)\end{array}$ & $\begin{array}{c}1.09 \\
(0.01)\end{array}$ & $\begin{array}{c}1.09 \\
(0.01)\end{array}$ & $\begin{array}{c}1.09 \\
(0.01)\end{array}$ \\
\hline $\begin{array}{l}\text { Estimated price } \\
\text { index }\end{array}$ & $\begin{array}{c}0.86 \\
(0.04)\end{array}$ & $\begin{array}{c}0.80 \\
(0.04)\end{array}$ & $\begin{array}{c}0.91 \\
(0.03)\end{array}$ & $\begin{array}{l}0.85 \\
(0.03)\end{array}$ & & \\
\hline at quarter of entry & & & & & & \\
\hline $\begin{array}{l}\text { Residual from last } \\
\text { sale price }\end{array}$ & & $\begin{array}{c}0.11 \\
(0.02)\end{array}$ & & $\begin{array}{c}0.11 \\
(0.02)\end{array}$ & & $\begin{array}{c}0.11 \\
(0.02)\end{array}$ \\
\hline $\begin{array}{l}\text { Months since last } \\
\text { sale }\end{array}$ & $\begin{array}{l}-0.0002 \\
(0.0001)\end{array}$ & $\begin{array}{l}-0.0003 \\
(0.0001)\end{array}$ & $\begin{array}{l}-0.0002 \\
(0.0001)\end{array}$ & $\begin{array}{l}-0.0003 \\
(0.0001)\end{array}$ & $\begin{array}{l}-0.0002 \\
(0.0001)\end{array}$ & $\begin{array}{l}-0.0003 \\
(0.0001)\end{array}$ \\
\hline $\begin{array}{l}\text { Dummy variables } \\
\text { for } \\
\text { quarter of entry }\end{array}$ & No & No & No & No & Yes & Yes \\
\hline Constant & $\begin{array}{l}-0.77 \\
(0.14) \\
\end{array}$ & $\begin{array}{l}-0.70 \\
(0.14) \\
\end{array}$ & $\begin{array}{l}-0.84 \\
(0.13) \\
\end{array}$ & $\begin{array}{l}-0.77 \\
(0.14) \\
\end{array}$ & $\begin{array}{l}-0.88 \\
(0.10)\end{array}$ & $\begin{array}{l}-0.86 \\
(0.10)\end{array}$ \\
\hline $\mathrm{R}^{2}$ & 0.85 & 0.86 & 0.86 & 0.86 & 0.86 & 0.86 \\
\hline
\end{tabular}


LOSS is defined as the greater of the difference between the previous selling price and the estimated value in the quarter of entry, and zero. LTV is the greater of the difference between the ratio of loan to value and 0.8 , and zero. The standard errors are heteroskedasticity robust and corrected both for the multiple observations of the same property and for the estimation of Estimated Value in 1990, Estimated Price Index at Quarter of Entry, LTV and Residual of Last Sale. 


\section{Table III}

Loss Aversion and List Prices: Alternative Specifications

Dependent Variable: Log(Original Asking Price)

OLS equations, standard errors in parentheses

\begin{tabular}{|c|c|c|c|c|c|c|}
\hline & (1) & (2) & (3) & (4) & (5) & (6) \\
\hline \multirow[t]{3}{*}{ Variable } & All & All & All & All & Loan To & Loan To \\
\hline & listings & listings & listings & listings & Value & Value \\
\hline & & & & & $<0.5$ & $<0.5$ \\
\hline \multirow[t]{2}{*}{ LOSS } & 0.29 & 0.24 & 0.40 & 0.29 & 0.37 & 0.28 \\
\hline & $(0.09)$ & $(0.09)$ & $(0.07)$ & $(0.07)$ & $(0.10)$ & $(0.11)$ \\
\hline \multirow[t]{2}{*}{ REAL LOSS } & 0.06 & 0.01 & & & & \\
\hline & $(0.04)$ & $(0.04)$ & & & & \\
\hline \multirow[t]{2}{*}{ LTV } & 0.05 & 0.05 & 0.07 & 0.06 & & \\
\hline & $(0.01)$ & $(0.01)$ & $(0.01)$ & $(0.01)$ & & \\
\hline \multirow[t]{2}{*}{ Estimated value in 1990} & 1.09 & 1.09 & 1.09 & 1.09 & 1.09 & 1.09 \\
\hline & $(0.01)$ & $(0.01)$ & $(0.01)$ & $(0.01)$ & $(0.02)$ & $(0.02)$ \\
\hline Estimated price index at & 0.86 & 0.80 & 0.91 & 0.83 & 0.75 & 0.72 \\
\hline quarter of entry & $(0.03)$ & $(0.03)$ & $(0.04)$ & $(0.04)$ & $(0.05)$ & $(0.05)$ \\
\hline \multirow[t]{2}{*}{ Residual from last sale price } & & 0.11 & & 0.10 & & 0.06 \\
\hline & & $(0.02)$ & & $(0.02)$ & & $(0.02)$ \\
\hline Estimated price index at & & & -0.10 & -0.06 & & \\
\hline quarter of last sale & & & $(0.02)$ & $(0.02)$ & & \\
\hline \multirow[t]{2}{*}{ Months since last sale } & -0.0004 & -0.0003 & -0.0004 & -0.0004 & 0.0004 & 0.0003 \\
\hline & $(0.0001)$ & $(0.0001)$ & $(0.0001)$ & $(0.0001)$ & $(0.0002)$ & $(0.0002)$ \\
\hline \multirow[t]{2}{*}{ Constant } & -0.78 & -0.70 & -0.74 & -0.69 & -0.75 & -0.69 \\
\hline & $(0.14)$ & $(0.14)$ & $(0.14)$ & $(0.14)$ & $(0.20)$ & $(0.20)$ \\
\hline $\mathrm{R}^{2}$ & 0.85 & 0.86 & 0.86 & 0.86 & 0.84 & 0.84 \\
\hline Number of observations & 5,792 & 5,792 & 5,792 & 5,792 & 1,999 & 1,999 \\
\hline
\end{tabular}

See Notes to Table II 


\section{Table IV}

Loss Aversion and List Prices: Owner-Occupants versus Investors

Dependent variable: $\log ($ Original asking price)

OLS equations, standard errors in parentheses

\begin{tabular}{|c|c|c|c|c|}
\hline & (1) & (2) & (3) & (4) \\
\hline Variable & All listings & All listings & All listings & All listings \\
\hline \multirow[t]{2}{*}{ LOSS X owner-occupant } & 0.50 & 0.42 & 0.66 & 0.58 \\
\hline & $(0.09)$ & $(0.09)$ & $(0.08)$ & $(0.09)$ \\
\hline \multirow[t]{2}{*}{ LOSS X investor } & 0.24 & 0.16 & 0.58 & 0.49 \\
\hline & $(0.12)$ & $(0.12)$ & $(0.06)$ & $(0.06)$ \\
\hline \multirow[t]{2}{*}{ LOSS-squared X owner-occupant } & & & -0.16 & -0.17 \\
\hline & & & $(0.14)$ & $(0.15)$ \\
\hline \multirow[t]{2}{*}{ LOSS-squared X investor } & & & -0.30 & -0.29 \\
\hline & & & $(0.02)$ & $(0.02)$ \\
\hline \multirow[t]{2}{*}{ LTV X owner-occupant } & 0.03 & 0.03 & 0.01 & 0.01 \\
\hline & $(0.02)$ & $(0.02)$ & $(0.01)$ & $(0.01)$ \\
\hline \multirow[t]{2}{*}{ LTV X investor } & 0.053 & 0.053 & 0.02 & 0.02 \\
\hline & $(0.027)$ & $(0.027)$ & $(0.02)$ & $(0.02)$ \\
\hline \multirow[t]{2}{*}{ Dummy for investor } & -0.02 & -0.02 & -0.03 & -0.03 \\
\hline & $(0.014)$ & $(0.01)$ & $(0.01)$ & $(0.01)$ \\
\hline \multirow[t]{2}{*}{ Estimated value in 1990} & 1.09 & 1.09 & 1.09 & 1.09 \\
\hline & $(0.01)$ & $(0.01)$ & $(0.01)$ & $(0.01)$ \\
\hline \multirow{2}{*}{$\begin{array}{l}\text { Estimated price index at quarter of } \\
\text { entry }\end{array}$} & 0.84 & 0.80 & 0.86 & 0.82 \\
\hline & $(0.05)$ & $(0.04)$ & $(0.04)$ & $(0.04)$ \\
\hline \multirow[t]{2}{*}{ Residual from last sale price } & & 0.08 & & 0.08 \\
\hline & & $(0.02)$ & & $(0.02)$ \\
\hline \multirow[t]{2}{*}{ Months since last sale } & -0.0002 & -0.0003 & -0.0001 & -0.0002 \\
\hline & $(0.0002)$ & $(0.00015)$ & $(0.0001)$ & $(0.0001)$ \\
\hline
\end{tabular}




\begin{tabular}{lcccc} 
Constant & -0.80 & -0.76 & -.86 & -.84 \\
& $(0.16)$ & $(0.16)$ & $(0.14)$ & $(0.16)$ \\
\hline $\mathrm{R}^{2}$ & 0.85 & 0.85 & 0.86 & 0.86 \\
Number of Observations & 3,687 & 3,687 & 3,687 & 3,687 \\
\hline P-value for test: Coefs on Loss and & 0.04 & 0.03 & 0.03 & 0.02 \\
LTV are equal, Owner-Occupants \& & & & & \\
Investor & & & & \\
\hline
\end{tabular}

See notes to Table II 


\section{Table V}

Loss Aversion and List Prices: Sold and Unsold Properties

Dependent variable: $\log ($ Original asking price)

OLS equations, standard errors in parentheses

\begin{tabular}{|c|c|c|c|c|}
\hline Variable & $\begin{array}{c}(1) \\
\text { All listings }\end{array}$ & $\begin{array}{c}\text { (2) } \\
\text { All listings }\end{array}$ & $\begin{array}{c}(3) \\
\text { All listings }\end{array}$ & $\begin{array}{c}\text { (4) } \\
\text { All listings }\end{array}$ \\
\hline \multirow[t]{2}{*}{ LOSS X unsold } & 0.45 & 0.34 & 0.61 & 0.50 \\
\hline & $(0.06)$ & $(0.06)$ & $(0.06)$ & $(0.06)$ \\
\hline \multirow[t]{2}{*}{ LOSS X sold } & 0.27 & 0.16 & 0.60 & 0.49 \\
\hline & $(0.08)$ & $(0.08)$ & $(0.04)$ & $(0.04)$ \\
\hline \multirow[t]{2}{*}{ LOSS-squared X unsold } & & & -0.16 & -0.16 \\
\hline & & & $(0.09)$ & $(0.09)$ \\
\hline \multirow[t]{2}{*}{ LOSS-squared X sold } & & & -0.29 & -0.29 \\
\hline & & & $(0.02)$ & $(0.02)$ \\
\hline \multirow[t]{2}{*}{ LTV X unsold } & 0.04 & 0.04 & 0.03 & 0.03 \\
\hline & $(0.02)$ & $(0.02)$ & $(0.01)$ & $(0.01)$ \\
\hline \multirow[t]{2}{*}{ LTV X sold } & 0.06 & 0.06 & 0.03 & 0.02 \\
\hline & $(0.02)$ & $(0.02)$ & $(0.01)$ & $(0.01)$ \\
\hline \multirow[t]{2}{*}{ Dummy for sold } & -0.03 & -0.03 & -0.03 & -0.04 \\
\hline & $(0.01)$ & $(0.01)$ & $(0.01)$ & $(0.01)$ \\
\hline \multirow[t]{2}{*}{ Estimated value in 1990} & 1.09 & 1.09 & 1.09 & 1.10 \\
\hline & $(0.01)$ & $(0.01)$ & $(0.01)$ & $(0.01)$ \\
\hline \multirow{2}{*}{$\begin{array}{l}\text { Estimated price index at quarter of } \\
\text { entry }\end{array}$} & 0.88 & 0.81 & 0.93 & 0.86 \\
\hline & $(0.04)$ & $(0.03)$ & $(0.03)$ & $(0.03)$ \\
\hline \multirow[t]{2}{*}{ Residual from last sale price } & & 0.11 & & 0.11 \\
\hline & & $(0.02)$ & & $(0.02)$ \\
\hline \multirow[t]{2}{*}{ Months since last sale } & -0.0002 & -0.0003 & -0.0002 & -0.0003 \\
\hline & $(0.0001)$ & $(0.0001)$ & $(0.0001)$ & $(0.0001)$ \\
\hline
\end{tabular}




\begin{tabular}{lcccc} 
Constant & -0.83 & -0.76 & -.89 & -0.82 \\
& $(0.14)$ & $(0.14)$ & $(0.14)$ & $(0.14)$ \\
\hline $\mathrm{R}^{2}$ & 0.86 & 0.86 & 0.86 & 0.86 \\
Number of observations & 5,792 & 5,792 & 5,792 & 5,792 \\
\hline P-value for test: Coefs on LOSS and & 0.09 & 0.06 & 0.07 & 0.06 \\
LTV are equal, Sold and Unsold & & & & \\
Properties & & & & \\
\hline
\end{tabular}

See Notes to Table 2. 


\section{Table VI}

Loss Aversion and Transaction Prices

Dependent variable: $\log ($ Transaction price)

NLLS equations, standard errors in parentheses

\begin{tabular}{lcc}
\hline & $(1)$ & $(2)$ \\
Variable & All & All \\
& listings & 0.03 \\
LOSS & 0.18 & $(0.08)$ \\
& $(0.03)$ & 0.06 \\
LTV & 0.07 & $(0.01)$ \\
Residual from last sale price & $(0.02)$ & 0.16 \\
& & $(0.02)$ \\
Months since last sale & & -0.0004 \\
& -0.0001 & $(0.0001)$ \\
\hline Nummy variables for quarter of entry & $(0.0001)$ & Yes \\
\hline
\end{tabular}

Nonlinear least squares estimation of the equation $\mathrm{P}=\mathrm{X} \beta+\mathrm{T} \theta+m \mathrm{LOSS}+g \mathrm{LTV}$, where $\mathrm{LOSS}=\left(\mathrm{P}^{0}-\mathrm{X} \beta-\mathrm{T} \theta\right), \mathrm{X}$ is a vector of property attributes, $\mathrm{T}$ is a set of dummies for the quarter of sale, $\mathrm{P}^{0}$ is the previous sale price and LTV is as defined in Tables 2 . In column (2), the right hand side is expanded to include a term that for observations with a previous sale prior to 1990 equals the Residual from the Last Sale, as in the previous tables, and for the remaining observations is equal to $\left(\mathrm{P}^{0}-\mathrm{X} \beta-\mathrm{S} \theta\right)$ where $\mathrm{S}$ is a set of dummies for the quarter of previous sale, of the same dimension and mapping as T. LTV is the greater of the difference between the ratio of loan to value and zero. The standard errors are heteroskedasticity robust and corrected for multiple observations of the same property. 


\section{Table VII}

\section{Hazard Rate of Sale}

Duration variable is the number of weeks the property is listed on the market

Cox proportional hazard equations, standard errors in parentheses

\begin{tabular}{lcccc}
\hline & $(1)$ & $(2)$ & $(3)$ & $(5)$ \\
Variable & All & All & All & All \\
& listings & listings & listings & listings \\
\hline LOSS & -0.33 & -0.63 & -0.59 & -0.90 \\
& $(0.13)$ & $(0.15)$ & $(0.16)$ & $(0.18)$ \\
LOSS-squared & & & 0.27 & 0.28 \\
& & & $(0.07)$ & $(0.07)$ \\
LTV & -0.08 & -0.09 & -0.06 & -0.06 \\
& $(0.04)$ & $(0.04)$ & $(0.04)$ & $(0.04)$ \\
Estimated value in 1990 & 0.27 & 0.27 & 0.27 & 0.27 \\
& $(0.04)$ & $(0.04)$ & $(0.04)$ & $(0.04)$ \\
Residual from last sale & & 0.29 & & 0.29 \\
Number of observations & & $(0.07)$ & & $(0.07)$ \\
Mummy variables for quarter of entry & yes & yes & yes & yes \\
\hline Months since last sale & -26104.4 & -26094.1 & -26101.8 & -26091.3 \\
& 5,792 & 5,792 & 5,792 & 5,792 \\
\hline
\end{tabular}

See Notes to Table 2. 


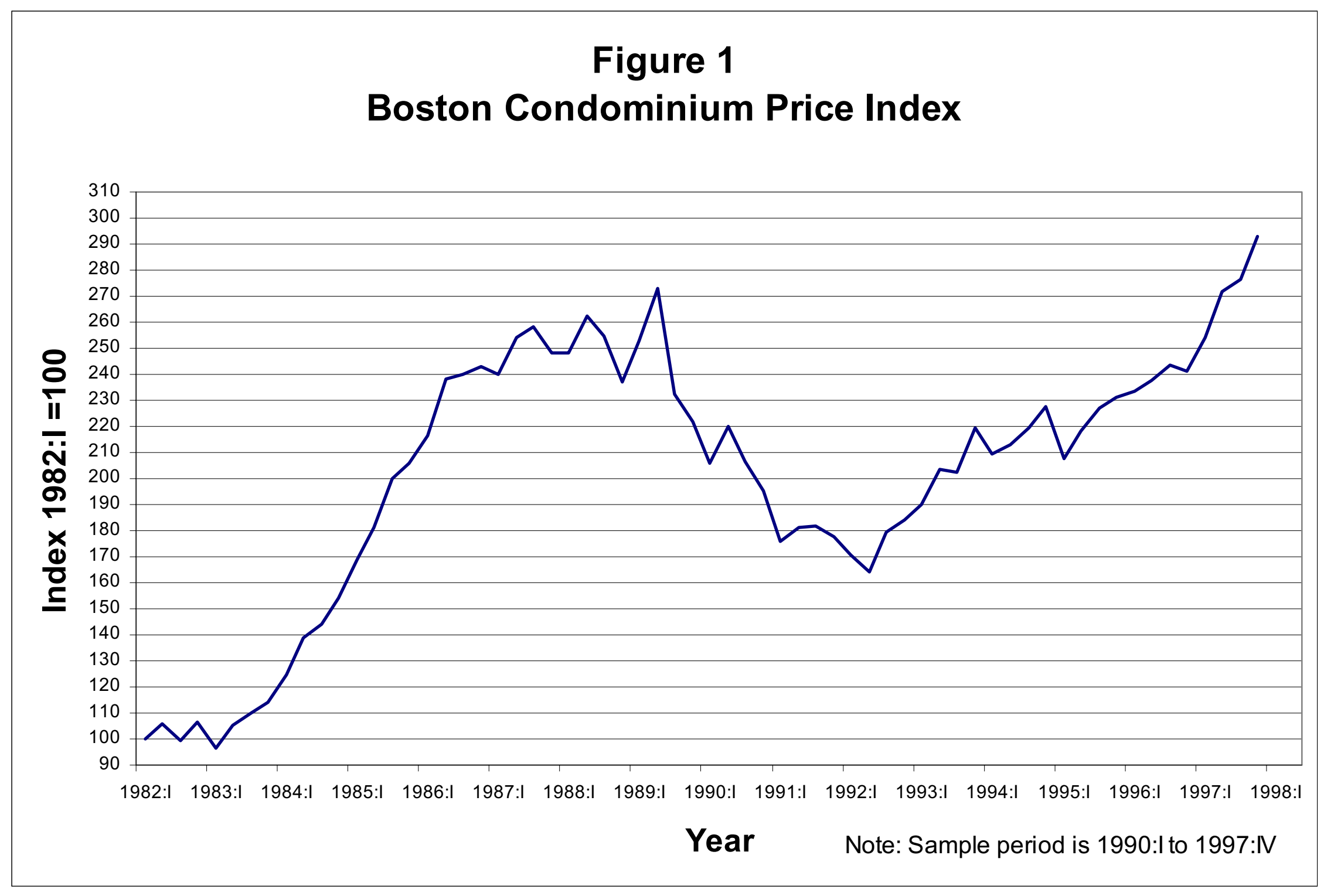


Figure 2

\section{Prospect Theory}

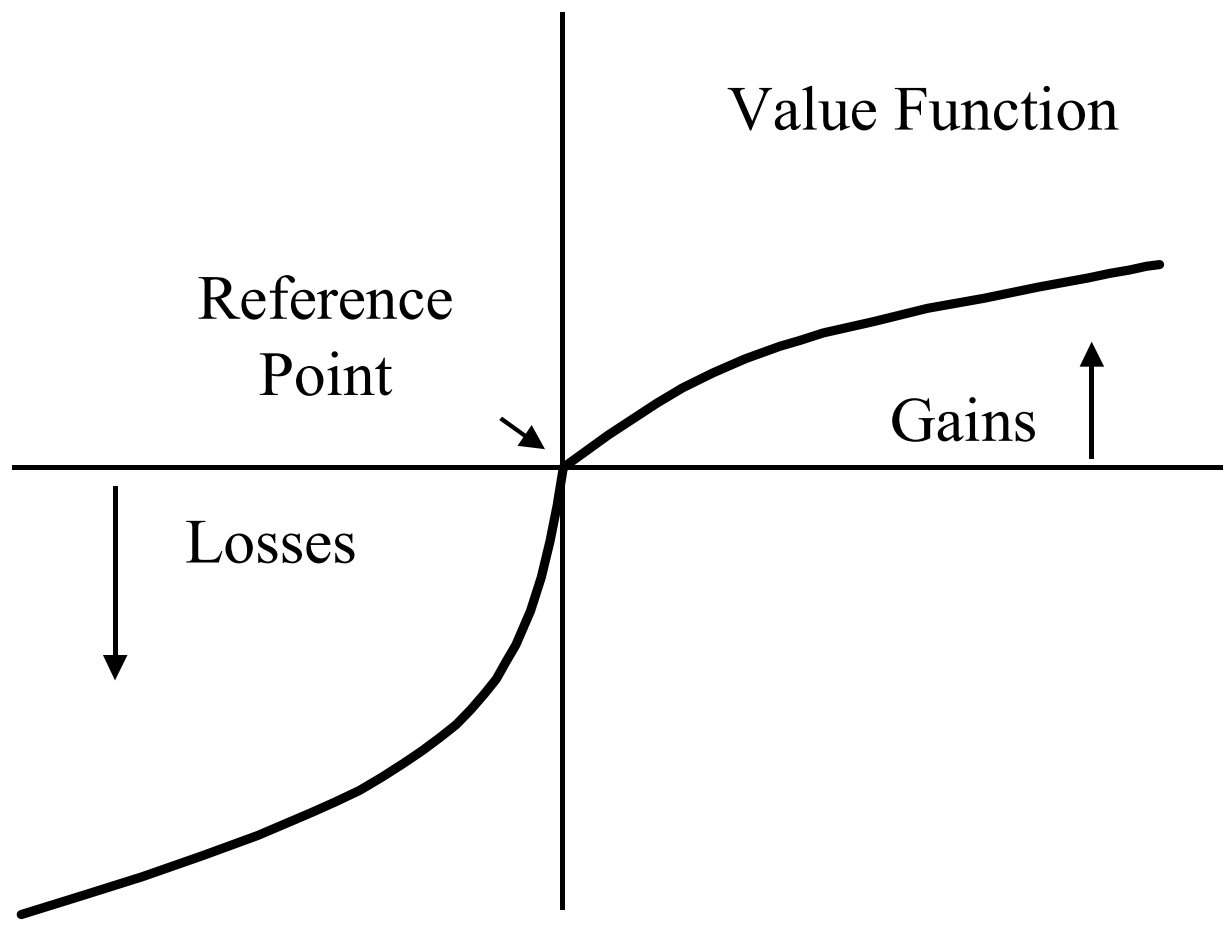

